\title{
Magnetite nanoparticles as-prepared and dispersed in Copaiba oil: study using magnetic measurements and Mössbauer spectroscopy
}

\author{
Michael I. Oshtrakh • Mikhail V. Ushakov • Anna S. Semenova • \\ Dina G. Kellerman • Vladimir Šepelák • Alfonso F. R. Rodriguez • \\ Vladimir A. Semionkin • Paulo C. Morais
}

Published online: 25 October 2012

(C) Springer Science+Business Media Dordrecht 2012

\begin{abstract}
Study of magnetite nanoparticles, as-prepared and dispersed in Copaiba oil as magnetic fluid, by means of magnetic measurement and Mössbauer spectroscopy at various temperatures demonstrated differences in the saturation magnetization
\end{abstract}

M. I. Oshtrakh (凶) · M. V. Ushakov · V. A. Semionkin

Department of Physical Techniques and Devices for Quality Control, Institute of Physics and Technology, Ural Federal University, Ekaterinburg 620002, Russian Federation e-mail: oshtrakh@gmail.com

M. I. Oshtrakh · M. V. Ushakov · V. A. Semionkin

Department of Experimental Physics, Institute of Physics and Technology,

Ural Federal University, Ekaterinburg 620002, Russian Federation

A. S. Semenova $\cdot$ D. G. Kellerman

Institute of Solid State Chemistry, Ural Branch , Russian Academy of Sciences,

Ekaterinburg 620990, Russian Federation

D. G. Kellerman

Department of Analytical Chemistry, Institute of Natural Sciences, Ural Federal University, Ekaterinburg 620002, Russian Federation

V. Šepelák

Institute of Nanotechnology, Karlsruhe Institute of Technology,

Hermann-von-Helmholtz-Platz 1, 76344 Eggenstein-Leopoldshafen, Germany

A. F. R. Rodriguez

Universidade Federal do Acre, Rio Branco, AC 69915-900, Brazil

P. C. Morais

Instituto de Física, Núcleo de Física Aplicada, Universidade de Brasília,

Brasília, DF 70910-900, Brazil

P. C. Morais

Department of Control Science and Engineering, Huazhong University of Science and Technology, Wuhan 430074, China 
and Mössbauer hyperfine parameters which were related to the interactions of Copaiba oil polar molecules with iron cations on magnetite nanoparticle's surface.

Keywords Mössbauer spectroscopy • Magnetic measurements • Magnetite nanoparticles $\cdot$ Magnetic fluids

\section{Introduction}

Magnetite nanoparticles appeared to be useful in the development of magnetic fluids for various biomedical applications such as drug delivery, contrast agent for magnetic resonance imaging, hyperthermia, etc. (see, for instance, $[1,2]$ ). It is important to assess information regarding the effect of the interaction of nanoparticle's surface with a hosted fluid. For this reason we studied nanosized magnetite as-prepared $\left(\mathrm{Fe}_{3} \mathrm{O}_{4}\right)$ and dispersed in Copaiba oil $\left(\mathrm{Fe}_{3} \mathrm{O}_{4}-\mathrm{CO}\right)$ as a magnetic fluid sample using magnetic measurements and ${ }^{57} \mathrm{Fe}$ Mössbauer spectroscopy at various temperatures.

\section{Experimental}

Magnetite $\left(\mathrm{Fe}_{3} \mathrm{O}_{4}\right)$ nanoparticles were synthesized by co-precipitation of a heated mixture of ferrous and ferric chloride aqueous solutions with concentrated ammonia (25 \% v.v.), under vigorous stirring. After precipitation of nanosized iron oxide particles and repeated washing using hydrochloric acid a stable sol at $\mathrm{pH} 2$ with the nanoparticle volume fraction of about $1 \%$ was produced. Copaiba oil was collected from Copaifera tree (Copaifera Langsdorffii Desf.) in the Ji-Paraná region, Rondônia State, Brazil. Copaiba oil dispersed in cyclohexane was then added to the as-produced sol under stirring. The resulting suspension was dried to remove out the organic solvent whereas the precipitated samples $\left(\mathrm{Fe}_{3} \mathrm{O}_{4}-\mathrm{CO}\right)$ as well as as-prepared $\mathrm{Fe}_{3} \mathrm{O}_{4}$ nanoparticles were used for magnetic and Mössbauer measurement.

The phase analysis of $\mathrm{Fe}_{3} \mathrm{O}_{4}$ and $\mathrm{Fe}_{3} \mathrm{O}_{4}-\mathrm{CO}$ samples was performed by means of $\mathrm{X}$-ray powder diffraction (XRD) with a scanning rate of $0.025 \%$ in $2 \Theta$ range from 20 to $120^{\circ}$ using a Bruker D8 Advance diffractometer with $\mathrm{Cu} \mathrm{K}_{\alpha}$ radiation. The morphology (shape and size) of the as-prepared $\mathrm{Fe}_{3} \mathrm{O}_{4}$ nanoparticles was studied by scanning electron microscopy (SEM) using a Quanta 2000 and an image corrected FEI Titan 80-300. Images were recorded using a Gatan US1000 slow-scan CCD camera. Prior to TEM investigations, powders were crushed in a mortar, dispersed in ethanol, and fixed on a copper-supported carbon grid. Magnetic measurements were carried out using a VSM-5T (Cryogenic Ltd.) magnetometer. Mössbauer spectra were measured at 295 and $90 \mathrm{~K}$ in 4096 channels using an automated precision Mössbauer spectrometric system, built on the base of the SM-2201 spectrometer with a high velocity resolution and liquid nitrogen cryostat with moving absorber. Additionally, Mössbauer spectra were measured at $21 \mathrm{~K}$ in 512 channels using a conventional Wissel spectrometer with a low velocity resolution and a commercial cryostat (Oxford Instruments). The detailed characteristics of equipment, the data acquisition and their treatment are given elsewhere [3-5]. 

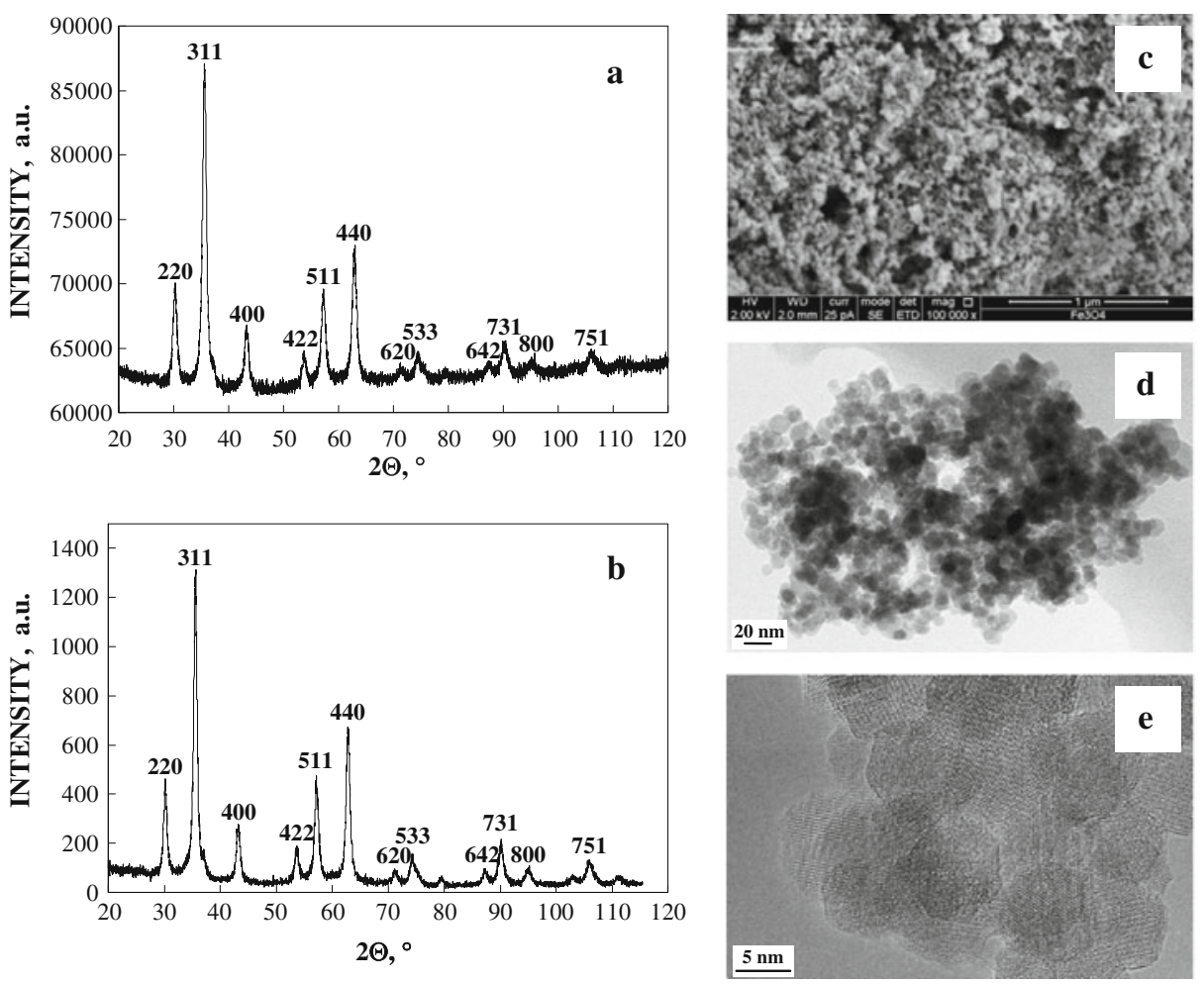

Fig. 1 X-ray diffraction patterns of as-prepared $\mathrm{Fe}_{3} \mathrm{O}_{4}$ (a) and $\mathrm{Fe}_{3} \mathrm{O}_{4}-\mathrm{CO}$ (b) samples, $\mathrm{SEM}$ (c), TEM (d) and high-resolution TEM (e) images of as-prepared $\mathrm{Fe}_{3} \mathrm{O}_{4}$
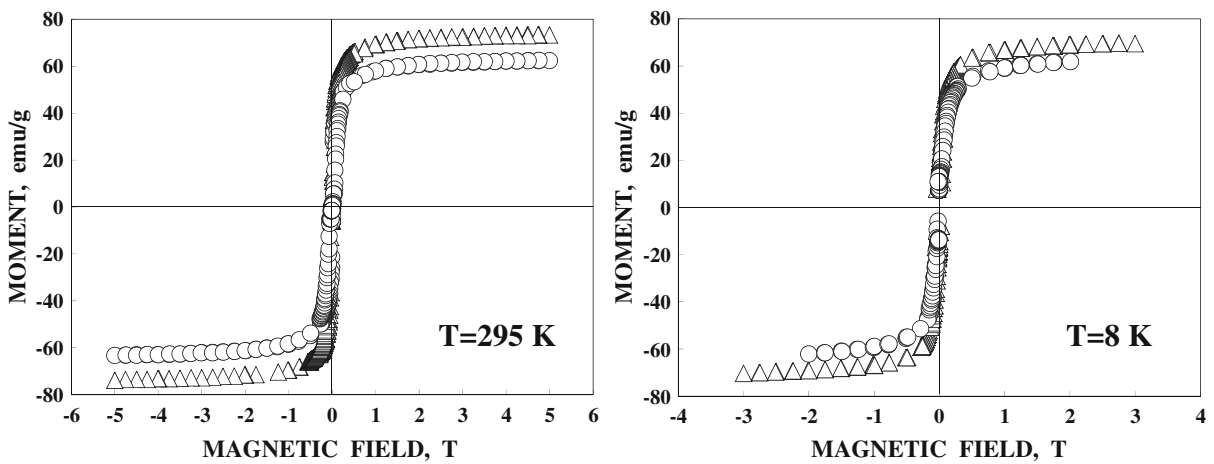

Fig. 2 Magnetization curves for $\mathrm{Fe}_{3} \mathrm{O}_{4}(\bigcirc)$ and $\mathrm{Fe}_{3} \mathrm{O}_{4}-\mathrm{CO}(\triangle)$ measured at 295 and $8 \mathrm{~K}$. The mass for $\mathrm{Fe}_{3} \mathrm{O}_{4}$ in the sample of $\mathrm{Fe}_{3} \mathrm{O}_{4}-\mathrm{CO}$ was determined using TG measurement

\section{Results and discussion}

XRD patterns of the as-prepared $\mathrm{Fe}_{3} \mathrm{O}_{4}$ and $\mathrm{Fe}_{3} \mathrm{O}_{4}-\mathrm{CO}$ samples are shown in Fig. 1a, b. Both patterns demonstrated the presence of the same spinel phase. A 

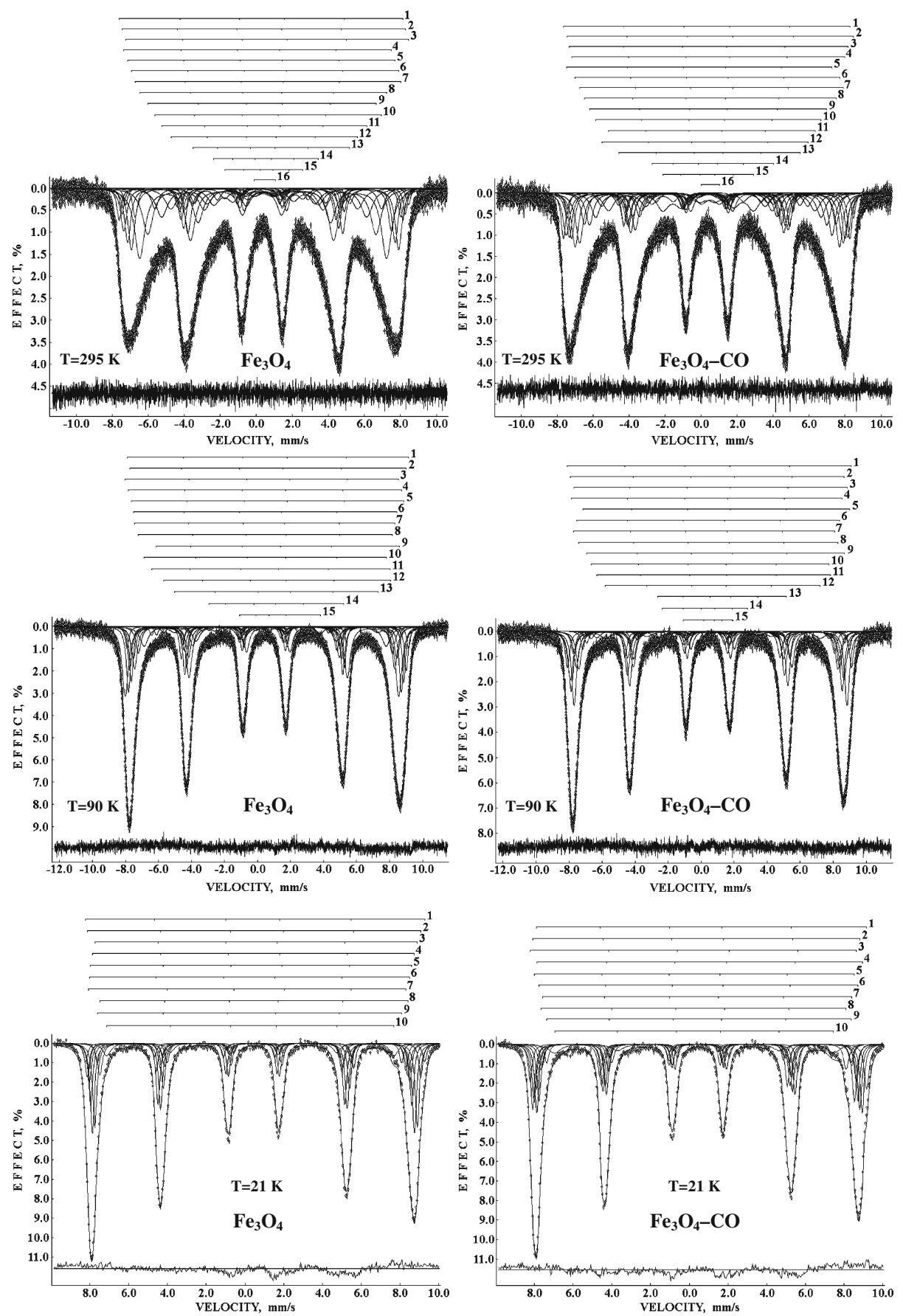

Fig. 3 Mössbauer spectra of as-prepared $\mathrm{Fe}_{3} \mathrm{O}_{4}$ and $\mathrm{Fe}_{3} \mathrm{O}_{4}-\mathrm{CO}$ samples measured at different temperatures with a high $(295$ and $90 \mathrm{~K})$ and low $(21 \mathrm{~K})$ velocity resolution. Indicated components are the results of the better fits. Differential spectra are shown below to indicate the quality of the fit 

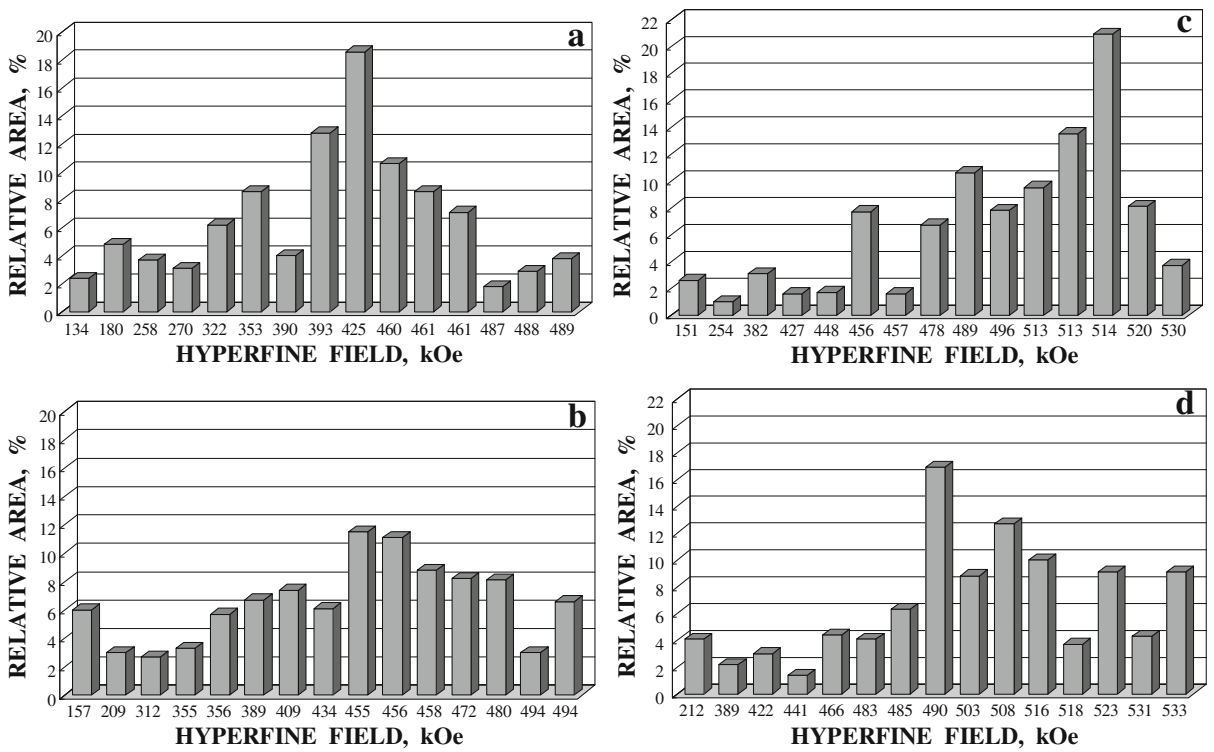

Fig. 4 Histograms of the relative areas of magnetic sextets obtained from the better fits of Mössbauer spectra of as-prepared $\mathrm{Fe}_{3} \mathrm{O}_{4}(\mathbf{a}, \mathbf{b})$ and $\mathrm{Fe}_{3} \mathrm{O}_{4}-\mathrm{CO}(\mathbf{c}, \mathbf{d})$ samples measured at $295 \mathrm{~K}$ $(\mathbf{a}, \mathbf{c})$ and $90 \mathrm{~K}(\mathbf{b}, \mathbf{d})$

representative SEM, TEM and high-resolution TEM micrographs of the as-prepared $\mathrm{Fe}_{3} \mathrm{O}_{4}$ nanoparticles are shown in Fig. 1c, d, e. HRTEM micrograph reveals a roughly spherically-shaped nanoparticles with an average size of $8 \mathrm{~nm}$ and a relatively narrow size distribution ranging from 5 to about $18 \mathrm{~nm}$.

Magnetization measurements at 295 and $8 \mathrm{~K}$ revealed clear differences in the saturation magnetization values for as-prepared $\mathrm{Fe}_{3} \mathrm{O}_{4}$ and $\mathrm{Fe}_{3} \mathrm{O}_{4}-\mathrm{CO}$ samples (Fig. 2). Our experimental findings are in very good agreement with the literature, as molecular surface passivation of nanosized cubic ferrite-based particles enhances the saturation magnetization values while improving the nanoparticle's crystalline quality [6].

Mössbauer spectra of both, as-prepared $\mathrm{Fe}_{3} \mathrm{O}_{4}$ and $\mathrm{Fe}_{3} \mathrm{O}_{4}-\mathrm{CO}$ nanoparticles, measured at 295, 90 and $21 \mathrm{~K}$ with a high and a low velocity resolution are shown in Fig. 3. These spectra exhibit asymmetric six-line patterns which are strongly different from Mössbauer spectra of bulk magnetite or micron-sized magnetite particles consisting of two magnetic sextets related to the ${ }^{57} \mathrm{Fe}$ in octahedral [B] and tetrahedral (A) sites (see, for instance, $[7,8]$ ). Note that similar Mössbauer spectra were measured at 296 and $78 \mathrm{~K}$ for magnetite nanoparticles with the average size of about $10 \mathrm{~nm}$ [7]. It was shown that usual physical model with two magnetic sextets related to the ${ }^{57} \mathrm{Fe}$ nuclei in the $(\mathrm{A})$ and $[\mathrm{B}]$ sites is not suitable for the fitting of such spectra. The results of the better fits are shown in Fig. 3.

There is no exact physical model yet to explain a large number of magnetic components in the spectra. Nevertheless, we can suppose that they have origin in complicated nanoparticle's structure, surface and internal layers, different nanodomains, size effect, non-stoichiometry, interparticle interactions, etc. Differences 
in the spectra of the as-prepared $\mathrm{Fe}_{3} \mathrm{O}_{4}$ and $\mathrm{Fe}_{3} \mathrm{O}_{4}-\mathrm{CO}$ samples are clearly seen if the results of their fitting are presented in the form of histograms of the relative areas of sextets with different hyperfine magnetic fields (Fig. 4).

\section{Conclusion}

Comparative study of as-prepared $\mathrm{Fe}_{3} \mathrm{O}_{4}$ and $\mathrm{Fe}_{3} \mathrm{O}_{4}-\mathrm{CO}$ samples by means of magnetic measurements and Mössbauer spectroscopy demonstrated differences in the saturation magnetization and magnetic hyperfine fields for both samples. This fact may be a result of the interaction of polar molecules in Copaiba oil, such as kaurenoic acid, with iron cations at the nanoparticle's surface. We can also suggest that a large number of components in Mössbauer spectra of the samples may be a result of complicated core nanoparticles' structure and the presence of nanoparticles' ensemble.

Acknowledgements The authors thank Dr. S.V. Belikov and Dr. A.S. Yurovskikh (Ural Federal University, Ekaterinburg) for XRD measurements and Prof. I. Felner (The Hebrew University, Jerusalem) for SEM measurements. This work was supported by the basic financing from the Ministry of Science and Education of Russian Federation. M.V.U. is supported in part by the Ural Federal University development program for support of young scientists.

\section{References}

1. Morais, P.C., Santos, R.L., Pimenta, A.C.M., Azevedo, R.B., Lima, E.C.D.: Thin Solid Films 515, 266 (2006)

2. Pankhurst, Q.A., Thanh, N.K.T., Jones, S.K., Dobson, J.: J. Phys. D: Appl. Phys. 36, 224001 (2009)

3. Semionkin, V.A., Oshtrakh, M.I., Milder, O.B., Novikov, E.G.: Bull. Rus. Acad. Sci.: Phys. 74, $416(2010)$

4. Oshtrakh, M.I., Semionkin, V.A.: Spectrochim. Acta, Part A: Molec. Biomolec. Spectroscopy. doi:10.1016/j.saa.2012.03.020 (2012)

5. Oshtrakh, M.I., Šepelák, V., Rodriguez, A.F.R., Semionkin, V.A., Ushakov, M.V., Santos, J.G., Silveira, L.B., Marmolejo, E.M., De Souza Parise, M., Morais, P.C.: Spectrochim. Acta, Part A: Molec. Biomolec. Spectroscopy. doi:10.1016/j.saa.2012.02.080 (2012)

6. Soler, M.A.G., Lima, E.C.D., da Silva, S.W., Melo, T.F.O., Pimenta, A.C.M., Sinnecker, J.P., Azevedo, R.B., Garg, V.K., Oliveira, A.C., Novak, M.A., Morais, P.C.: Langmuir 23, 9611 (2007)

7. Goya, G.F., Berquo, T.S., Fonseca, F.C., Morales, M.P.: J. Appl. Phys. 94, 3520 (2003)

8. Wang, J., Yao, M., Xu, G., Cui, P., Zhao, J.: Mater. Chem. Phys. 113, 6 (2009) 